Author Posting. (C) The Authors 2012. This is the author's version of the work. For full bibliographic citation, please refer to Risk Analysis, 32, 6, 957-972). The definitive version is available at www.blackwell-synergy.com http://dx.doi.org/

(DOI: 10.1111/j.1539-6924.2011.01695.x)

\title{
The Psychological Distance of Climate Change
}

\author{
Alexa Spence ${ }^{a}$, Wouter Poortinga ${ }^{b}$ and Nick Pidgeon ${ }^{c}$
}

${ }^{a}$ Horizon Digital Economy Research / School of Psychology, University of Nottingham

${ }^{\mathrm{b}}$ Welsh School of Architecture / School of Psychology, Cardiff University.

${ }^{\mathrm{c}}$ Understanding Risk Research Group, School of Psychology, Cardiff University.

\section{Acknowledgements}

This research was supported by a research grant from the Economic and Social Research Council (RES-062-23-1134) as well as a Climate Change Leader Fellowship (RES-066-27-0013) and a major grant to the Understanding Risk research group from the Leverhulme Trust (F/00 407/AG). Additional support was received from Horizon Digital Economy Research, RCUK grant (EP/G065802/1). 


\begin{abstract}
Avoiding dangerous climate change is one of the most urgent social risk issues we face today and understanding related public perceptions is critical to engaging the public with the major societal transformations required in order to combat climate change. Analyses of public perceptions have indicated that climate change is perceived as distant on a number of different dimensions. However to date there has been no in depth exploration of the psychological distance of climate change. This study uses a nationally representative UK sample in order to systematically explore and characterise each of the four theorised dimensions of psychological distance - temporal, social and geographical distance, and uncertainty in relation to climate change. We examine how each of these different aspects of distance relates to each other as well as to concerns about climate change and sustainable behaviour intentions. Results indicate that climate change is actually both psychologically distant and proximal in relation to different dimensions. Lower psychological distance was generally associated with higher levels of concern; although certain aspects of greater psychological distance (perceptions of disproportionate impacts of climate change on developing countries) were also significantly related to preparedness to act on climate change. Findings support the idea that it is useful for risk communications regarding climate change to highlight both local and distant impacts of climate change where appropriate. Interestingly, our data indicates that whilst psychological distance communications are likely to be valuable in promoting concern about climate change, these may also be useful in promoting action amongst those already concerned about climate change.
\end{abstract}

KEYWORDS: climate change; global warming; psychological distance; risk perceeptions; sustainable behaviour; 


\section{INTRODUCTION}

Climate change is a major societal risk issue and there are increasing calls for urgent mitigating action. Public perceptions of climate change and its risks are critical to achieving the ambitious greenhouse gas emissions targets set in the UK and the US as well as in many other countries around the world (1). Meeting these targets will require major transformations in the way that countries manage and consume energy. On the supply side, public acceptance and uptake of new technologies is important whilst on the demand side, preparedness to change behaviour and to comply with new sustainability legislation will be important in alleviating the pressure put on our precious energy resources $(2,3)$. A key characteristic of climate change risks is that they are psychologically distant for many people $(4,5)$. This has provoked a variety of hypotheses about how the reduction of this distance, by making climate change more real, local, relevant and immediate, may help to promote action on climate change (6-8). Until now however, there has been no systematic exploration of the nature of the psychological distance that characterises climate change. In addition, there has been no investigation of the link between different aspects of perceived psychological distance and concern about, or willingness to take action on, climate change. We propose that a better understanding of this aspect of public perceptions of climate change is necessary in order to input into the formulation of effective risk communications in the promotion of mitigation efforts.

\subsection{Concern about of Climate Change}

Previous research on perceptions of climate change in the UK indicated that public awareness of the issue is high (9) with an overwhelming majority in 2005 believing that the world's climate is changing and that action should be taken against it $(10,11)$, However, 
research conducted over the past 3-4 years in both America and the UK shows some decline in levels of concern (e.g. 12, 13). In addition, and perhaps paradoxically, given the strengthening scientific evidence of the anthropogenic causes over that time, research over the past year also suggests that the public in both the Europe and the US may have started to become somewhat more sceptical and uncertain about the issue (12-14). Compounding this, the media controversy generated during the winter of 2009-2010 concerning e-mails from climate scientists at the University of East Anglia (15), and over glacial melting forecasts made by the Intergovernmental Panel on Climate Change (16), might additionally have served to reinforce uncertainty and scepticism amongst some sections of the public in both the UK (e.g. 17) and elsewhere.

\subsection{Psychological Distance and Construal Level Theory}

Despite declines observed in concern about climate change, overall levels remain high, both in the UK and across Europe (14). However many people do not behave in a sustainable fashion (18) and it has been suggested that this is partly due to climate change being perceived as a psychologically distant issue. In particular, research has indicated that people have traditionally thought that climate change risks only affect other people or nations, and those born far in the future $(7,19)$. Construal Level Theory (CLT), developed by Liberman and Trope (4), outlines four key dimensions of such psychological distance: spatial or geographical distance; temporal distance; distance between the perceiver and a social target, i.e. another individual or group; and hypotheticality, e.g., how certain is it that an event will happen. As Milfont recently highlighted (5), climate change is perceived to be distant on all of these dimensions, and therefore it is useful to look to CLT research in generating hypothesis about how these relate to one another in this domain and in exploring the potential that manipulating perceived distance may have as a 
method for promoting sustainable behavior change.

CLT proposes that psychological distance from an object or event is directly linked to the way that people mentally represent it. It is proposed that psychologically distant events are represented by abstract high-level construals composed of general decontextualised features, whereas psychologically close events are represented with concrete low-level construals made up of specific contextual details. Furthermore, it is thought that psychologically distant and close stimuli are respectively represented in similar mental space and that each dimension of distance is interrelated so that impacts on one aspect of distance can influence each other aspect of distance. These ideas are supported by a large amount of, primarily experimental, evidence. For example, studies have found that processing psychologically distant information (e.g. geographically distant) is facilitated when participants are focused on distant congruent stimuli (e.g. socially or temporally distant or uncertain), indicating that these are cognitively associated (20). Furthermore, performance on tasks that require abstraction (e.g. the Gestalt Completion Test) is found to improve when participants focus on psychological distance, e.g. a future time period (21-23) and vice versa for tasks that require a focus on specific details (22). Conversely, when people are encouraged to focus either on specific details or on more abstract ideas this is found to impact the distance at which the stimulus or event is considered. So for example, asking participants to focus on low-level 'how' details of an activity rather than high-level 'why' information leads participants to think about the activity as taking place at more distant points in time (24). In addition, evidence from neuropsychological research has demonstrated that the brain is hierarchically organized with abstract aspects of stimuli being found to be represented at higher points in the cortical hierarchy (25), again pointing to the idea that mentally the organization of stimuli may be divided this way. 
Notably, CLT points to the importance of psychological distance in promoting action (4). The utility of psychological distance in determining behavioural choices is perhaps counterintuitive considering that distant events may be more uncertain in nature. Interestingly though evidence demonstrates that focusing on distance helps people to make choices that are more in line with their more abstract, core considerations and therefore appears to help self control. In relation to this, psychologically distant representations seem to help people to make more confident predictions about the future, and to make clearer evaluations and behavioural choices (4). However these theoretical predictions appear to contradict ideas presented within goal setting theory, proposed by Locke and Latham in the 1990s, which highlight the importance of specific detailed goals (psychological closeness) in increasing the likelihood of action (26). Goal setting theory focuses on the development of conscious goals and how these influence task performance. A key finding here is that when people are asked to do their best, they tend not to perform as well as when they are given specific goals (27). This is because abstract goals have no external referent and thus can be defined idiosyncratically by the recipient of the message. In contrast, more specific goals are found to lead to higher task performance by reducing the ambiguity about what is to be attained (28). A huge amount of research supports these ideas and in fact, goals are thought to affect performance through four mechanisms: by directing attention and effort towards goal relevant activities (e.g. 29); by energizing the individual and increasing effort (e.g. 30, 31); by increasing persistence (e.g. 30); and by activating task relevant knowledge and strategies (32). Additionally, and building on goal setting theory, work around implementation intentions developed the idea that by specifically making plans that link situational cues (appropriate opportunities to act), with desired behavioural responses, then action can be encouraged (33). Notably, this focus on specific detail is (through CLT) linked 
with psychological closeness, resulting in two slightly different hypotheses. Psychological distance should lead to behavior that is more in line with an individual's core values however psychological closeness should encourage a person to act, given their improved ability to focus on the consequences of their actions. Interestingly, recent experimental research has indicated that a combination of both an abstract mindset and specific goals (or a specific mindset and abstract goals) may be most useful in promoting climate change related behavior (34). This points to the potential validity of both theoretical hypotheses and the possibility that these can complement rather than contradict each other. Indeed, the focus of CLT is clearly on how an abstract mindset encourages behavior in line with ideals whilst goal setting theory focuses on the best way of translating intentions into action. Here, we will explore the relationship between naturally arising perceptions of distance and preparedness to act to mitigate climate change and, in doing so, will consider the validity of each of these hypotheses in this domain.

\subsection{The Psychological Distance of Climate Change}

There is currently quite limited evidence examining construal level theory and psychological distance within the domain of climate change however there is a variety of disparate evidence that speaks to these issues. Polling evidence indicates that people generally perceive climate change as most likely to impact geographically and temporally distant people and places (35). In addition, climate change impacts tend to be viewed as more serious for distant locations (36). People also clearly distinguish between personal and societal impacts of climate change, with several studies finding that personal risks of climate change are judged to be lower than societal risks $(35,36)$. Note that these results are found within respondents in Britain and the US and that this may well be culturally bounded. Indeed the perception that climate change impacts may be 
more serious in developing countries, particularly those located in the geographic South may be quite accurate (37), and importantly, these are also likely to be the countries who do not have the resources and capability to deal with these impacts. In fact, whilst cross-national studies do indicate that respondents from developing countries tend to be more concerned about local environmental issues than those from industrialized nations $(38,39)$, beyond this a general spatial bias appears to exist where people in both developed and developing countries tend to perceive environmental degradation to be more serious at a global level than at a local level (3941). This again points to the importance of bridging this disassociation between local and global impacts of climate change in order to promote personal action. Interestingly Spence et al recently demonstrated that experience of flooding (i.e. an event that could be attributed to a changing climate) is significantly related to the way that individuals perceive climate change and the extent to which they are prepared to act on climate change (8). This implies that framing climate change in terms of local events and geography will help to make the issue more salient (7), will promote emotional and cognitive engagement with climate change (42-44), and will make the benefits of acting on climate change more tangible (6).

Bridging the temporal distance of climate change is also an important issue; the fact that discussions and debate around climate change are particularly focused on the prevention of future impacts may be particularly problematic for prompting action. Experimental research finds that people are more likely to take greater risks with regards to decisions that are further away in time (45). In addition, research indicates that people discount future costs and benefits in an inconsistent fashion. When considering benefits in the future compared to now, a particularly sharp discount rate tends to be applied, whereas discount rates applied to two time points in the future are much lower $(46,47)$. Asking people to act on climate change may be 
particularly unattractive then, given that this requires immediate actions undertaken for the promise of rewards that are quite distant in time, as well as uncertain in nature (48). Within this domain, Weber and colleagues have developed query theory, which elaborates on decision making about the future by considering the deliberation processes that are commonly used and postulates that in consumption decisions people tend to assess arguments for immediate consumption first and that this initial assessment interferes with any subsequent consideration of delaying consumption which tends to come second (49). By this theory, the option of delaying or reducing consumption is naturally at a disadvantage and, in fact, in support of this theory, intertemporal discounting has been greatly reduced by prompting people to consider the case for deferring consumption first, before considering the idea of immediate consumption. Note that this result could also be interpreted within construal level theory in that participants focusing on the case for deferring consumption first may be focused on a more distant time horizon than those considering immediate consumption. This may help individuals to overcome the psychological distance associated with delayed gratification and influence decision making. Indeed, environmental actions are generally considered as future orientated behaviours, and recent research by Rabinovich et al (50) found that focusing people on the future was found to increase consistency between environmental attitudes, and intentions and behaviour. A slightly different perspective on this might argue that focusing on climate change as something distant, particularly in terms of time, may mean that people feel that there is still opportunity to be able to contribute to mitigating future effects and encourage people of the value in acting sustainably.

\subsection{Scepticism and Uncertainty}

Another aspect of psychological distance that is discussed within construal level theory is 
uncertainty and this has received a lot of attention within current discourses on climate change, in particular alongside debate over scepticism (51). Indeed many commentators have been using the terms 'scepticism' and 'uncertainty' interchangeably and, to compound confusion, there is also uncertainty over scepticism, e.g. perceived agreement amongst scientists, and scepticism over uncertainty, e.g. perceptions of what is knowable about the future. Here, we will attempt to be more specific with the terminology used. Survey evidence indicates that whilst significant majorities of Europeans and Americans believe that climate change is anthropogenic $(11,13)$, some do perceive scientific disagreement on climate change $(52,53)$. In reality, there may be most scientific disagreement and uncertainty around the potential impacts of climate change. Climate systems, as well as the human and biological systems with which climate systems interact, are extremely complex and our understanding of how these systems operate is incomplete (54). The public also appear to be somewhat aware of this uncertainty, with approximately $40 \%$ of the British public supporting the idea that the climate system is too complex and uncertain for scientists to make useful forecasts (52). It is therefore important to be specific when discussing scepticism and uncertainty in relation to climate change and to consider where changes in these perceptions may actually be occurring.

Individuals who are sceptical about climate change are less likely to behave sustainably; clearly without the belief that climate change is happening, there is little point in acting on it. Similarly, the belief that climate change is anthropogenic is a necessary condition (although not sufficient) for considering that personal actions can have an impact on tackling climate change. In addition, people generally prefer certainty over uncertainty (a basic tenet of prospect theory: $55)$ and there is some evidence that uncertainty may be used as a justification for inaction (45, 56). Indeed, the communication of uncertainty has been related to a reduced willingness to act to 
mitigate negative environmental outcomes (57). However there has been relatively little consideration given to the relationship between uncertainty and other perceptions within the climate change domain.

\subsection{Current research}

Overall, there is a variety of research outlining the idea that climate change may be psychologically distant on several dimensions. Given the importance of behavior change in the context of meeting the challenging climate change targets we have been set, it is important to examine perceptions of climate change and ways of communicating the risks of climate change in order to promote sustainable behavior. Our review of the previous literature has indicated that there may be multiple ways of conceptualizing different dimensions of psychological distance within the domain of climate change. The current research therefore aims to provide a first comprehensive in depth exploration of the psychological distance dimensions of climate change, examining each proposed dimension of psychological distance in different ways where necessary to explore how these are best characterised in this domain, as well as how the different dimensions of psychological distance relate to one another.

Furthermore we will consider how perceived psychological distance relates to concern about climate change and related behaviour intentions. We consider two key lines of research in relation to the potential consequences of thinking about climate change as a distant or close issue. Construal level theory (4) indicates that greater psychological distance is associated with promoting action that is in line with people's abstract beliefs and core values. However, goal setting theory also points to the utility of goal specificity (linked to psychological closeness) in prompting behaviour (25) and there have been a number of suggestions that by making climate 
change more immediate, local, personally relevant and real, then people may be more likely to act. Our findings will therefore usefully feed into the debate on whether attempting to reduce the psychological distance of climate change risks is a useful strategy for promoting sustainable behaviour.

\section{METHOD}

Ipsos MORI collected survey data using Computer Assisted Personal Interviews (CAPI) between 5 January and 2 March 2010. A nationally representative quota sample, $N=1822$, of the population of Great Britain (i.e. England, Scotland and Wales), aged 15 years and older was obtained based on a core sample of 1,436 and additional booster samples from Scotland ( $\mathrm{n}=109)$ and Wales $(\mathrm{n}=185)$. Interviews were conducted at 315 sample points (including Scottish and Welsh booster samples) selected randomly from a stratified sample of output areas sorted by Government Office and council area. Within each sampled area, interviewers were asked to achieve set quotas for gender, age, and working status based on the known demographics of the local population of that area. This technique was used to ensure that key demographic groups were included appropriately in the sample obtained, ensuring that this was representative of the population even at the local level. Interviews were conducted by fully trained and supervised market research interviewers, with each interview taking approximately 30 minutes to complete* No incentives were provided for participation. The final participant sample obtained was composed of $48 \%$ male respondents and $52 \%$ female respondents, with a modal age bracket of $35-44$, with a large proportion of people who work full time, though also significant proportions of people who work part time or are retired, see Table I. This reflects the most recent available 
demographic statistics for the Great British population (gender and age figures were based on ONS 2007 mid-year population estimates while working status was based on 2001 Census data).

\subsection{Materials}

We designed the survey in order to examine public perceptions of energy futures and climate change, partly so as to provide current empirical data on perceptions and partly to provide greater insight into underlying reasons for perceptions held. The survey instrument was developed by a panel of four academic researchers and refined after input from the partner social research company, Ipsos MORI, and an expert advisory panel $(\mathrm{N}=15)$, comprised of academic researchers and members of relevant government departments and third sector groups.

Questions utilised examined a range of socio-cognitive constructs relating to energy and climate change, related behavioural intentions, and key demographic variables. Here we will focus on key constructs examining perceptions of climate change and those examining intentions to undertake sustainable behaviour, see XXX (58) for the full survey instrument and topline results. Questions assessing perceptions of climate change included those examining psychological distance dimensions and concern over climate change. Behavioural intentions examined participants' preparedness to reduce their energy use to help tackle climate change, see Appendix for full details of questions used.

Concern about climate change was measured using three similar questions which assessed general concerns, concerns about related personal impacts of climate change and concerns about related societal impacts. These were combined to form a reliable scale (Cronbach's $\alpha=0.83$ ).

\footnotetext{
* Given the use of non-probability quota sampling here we do not provide, and did not collect, data on response 
Psychological distance dimensions assessed were geographical distance, social distance, temporal distance and uncertainty. Perceived geographic distance of climate change was assessed using two key questions, one which assessed perceptions that climate change would impact distant locations and one that assessed perceptions that climate change would impact local areas. These were assessed separately because we acknowledged that the perceptions that climate change may primarily impact distant areas would not preclude the perception that climate change may also impact local areas. Two key hypothesised dimensions of social distance were also assessed. Questions assessed respondents' perceptions that climate change was likely to have an impact on people similar to themselves as well as the idea that climate change may disproportionally impact developing countries. All respondents were living in Britain and therefore the idea that climate change may have a greater impact on developing countries (considered to be socially distant from our respondents) focuses on one aspect of social distance in relation to climate change. We note that this is not incompatible with the idea that climate change will also impact people who are socially proximal to respondents.

Temporal distance was assessed with one direct question that asked respondents when they felt that Britain would start feeling the effects of climate change (based on a similar question used by Leiserowitz et al. (12)). Responses were recorded on a seven point scale which included different time scales along with options to select the idea that effects of climate change are already being felt or would never be felt. We also assessed a range of different aspects of uncertainty and climate change scepticism which have been variously discussed and debated in recent months including perceived causes of climate change, uncertainty over whether climate change is happening, perceived exaggeration of climate change, perceived scientific consensus 
on climate change and uncertainty over the effects of climate change.

All questions (apart from temporal distance) were answered on four or five point Likert type scales and all questions offered 'Don't know' and/or 'No opinion' response options as appropriate. However, due to low numbers of these responses these were deleted listwise for the correlational and regression analyses.

\section{RESULTS}

Data obtained was weighted to the profile of the known GB population on the basis of gender, age, working status, social grade and ethnicity.

\subsection{Characterising the Psychological Distance of Climate Change}

Questions assessed each of the four theorised aspects of psychological distance and basic descriptive analyses and comparison of these was undertaken first in order to explore and characterise the nature of perceived psychological distance in relation to climate change.

\subsubsection{Geographic, Social, and Temporal Distance}

More people disagreed than agreed with the idea that climate change would mostly affect areas that are far away, with $48.6 \%$ respondents who tended to or strongly disagreed with this statement (32.1\% tended to or strongly agreed), see Figure 1. Most also believed that their local areas are likely to be impacted by climate change, with $52.6 \%$ respondents who tended to or 
strongly agreed with this statement (30\% tended to or strongly disagreed). Generally therefore climate change did not appear to be viewed as a primarily geographically distant phenomenon.

With regards to social distance, a majority of respondents felt that climate change would disproportionally impact developing countries with $45.8 \%$ who tended to or strongly agreed with this idea (36.1\% tended to or strongly disagreed). However respondents also felt that climate change was likely to have an impact on people similar to themselves, and $44.6 \%$ of respondents tended to or strongly agreed with this statement (32.3\% tended to or strongly disagreed). So respondents seem to perceive social distance in that greater effects are likely to be experienced by developing countries, but also a lack of distance in that people similar to themselves would also be impacted. Of course these perceptions are entirely compatible with one another and may reflect the idea that climate change is global and will affect everyone.

Respondents primarily indicated that they felt the effects of climate change to be temporally close with $41 \%$ of respondents indicating that Britain is already feeling the effects of climate change, see Figure 2. Notably, very few respondents thought that the effects of climate change are more than 50 years away or would never happen. So temporally, at least some climate change impacts actually appear to be perceived as quite close. 


\section{Figure 1}

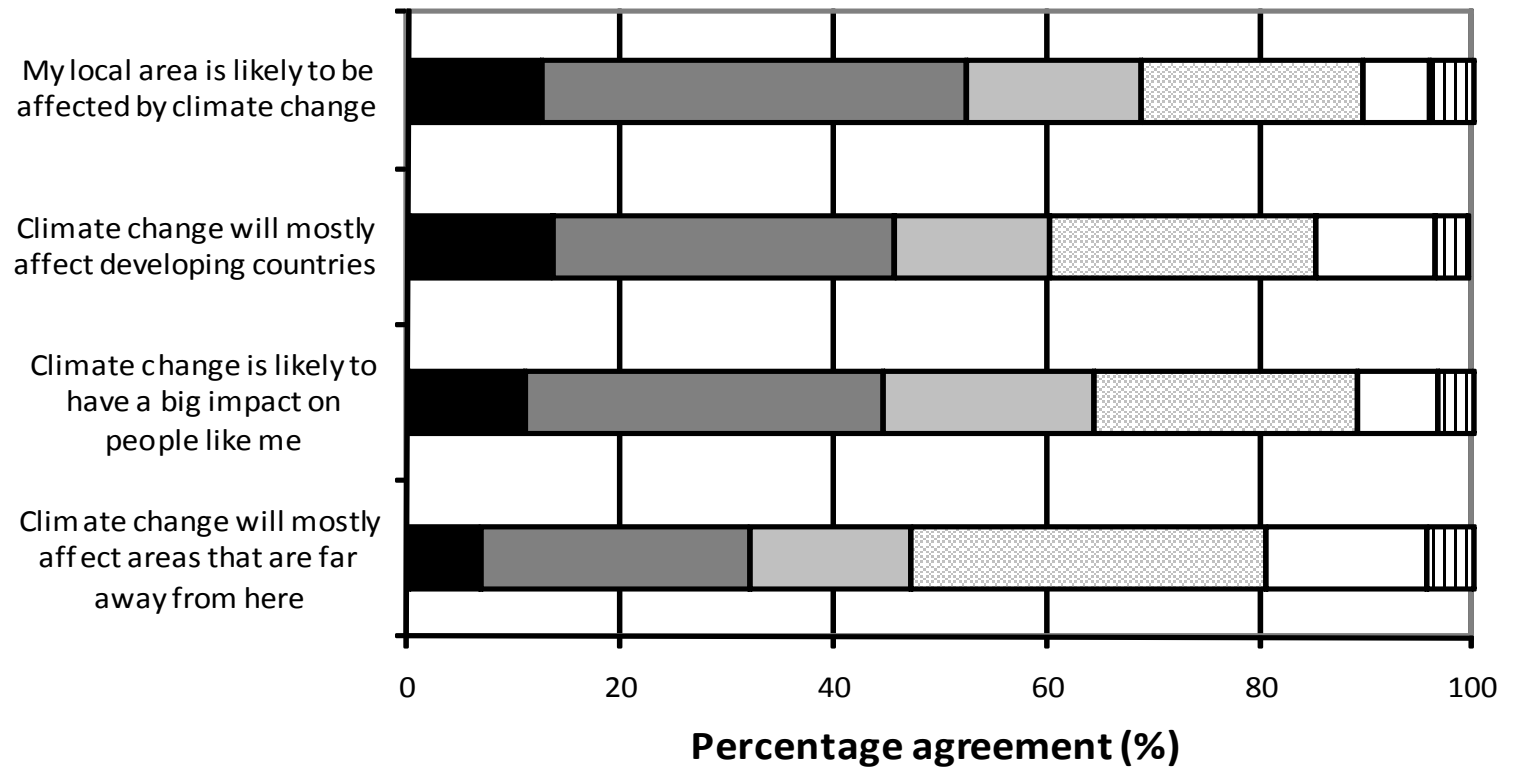




\section{Figure 2}

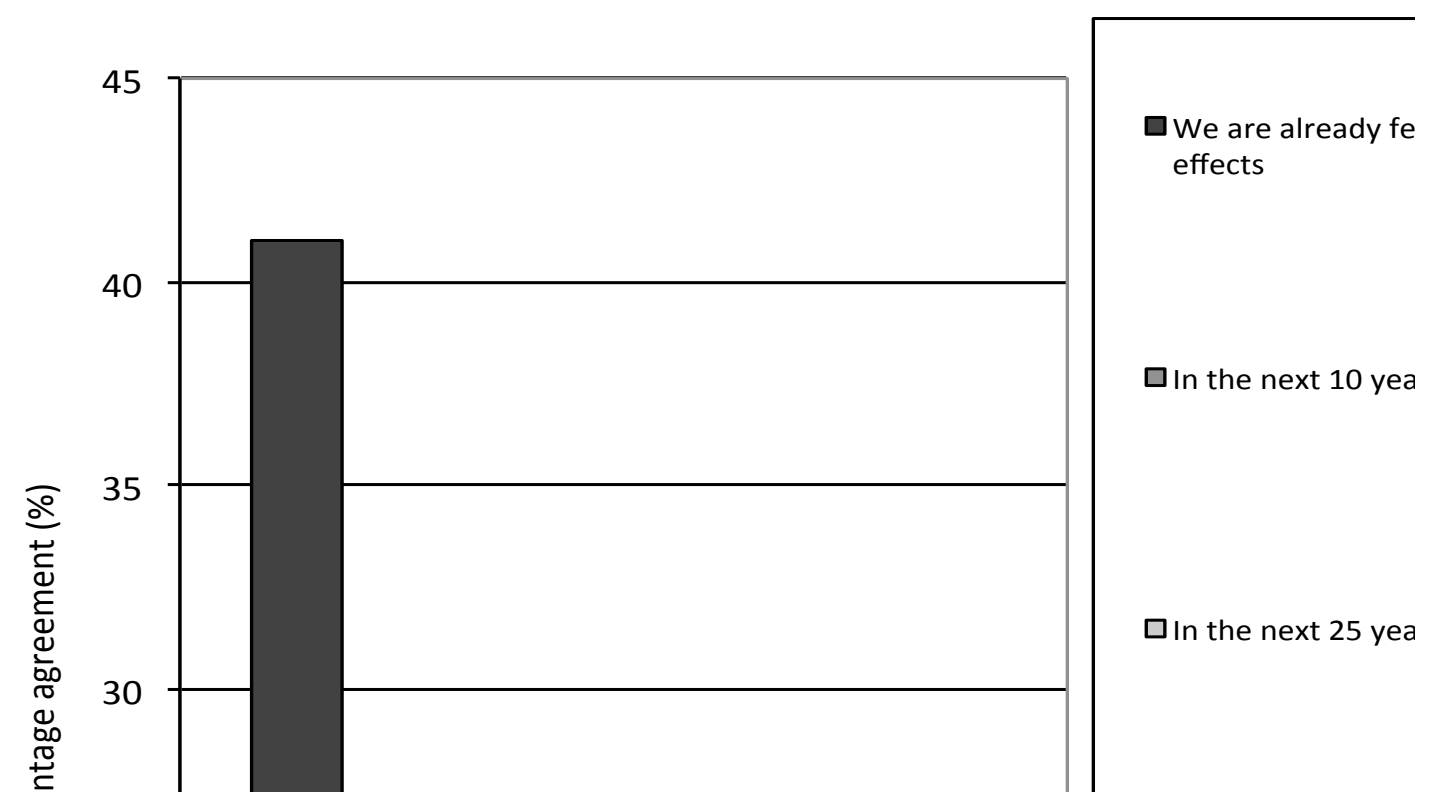

\subsubsection{Uncertainty and Scepticism about Climate Change}

Questions also assessed uncertainty associated with climate change alongside aspects of scepticism, given that these constructs are often confused and appear to be interrelated within discourses of climate change. One of the key aspects of this debate is scepticism over anthropogenic contributions to climate change. We asked people to think about the causes of climate change and to select from a number of statements which best described their opinion. People most commonly consider that climate change is caused by a combination of human activity and natural processes (47\%), whilst $31 \%$ feel that climate change is caused mostly or entirely by human activity, and $18 \%$ consider that it has mostly or entirely natural causes. So altogether a large majority, $78 \%$, of respondents indicated that they believe that human activity contributes to climate change in some way. Respondents were further asked to indicate their 
agreement with a series of statements regarding uncertainty and scepticism relating to different aspects of climate change. Interestingly, there was wide variation in perceptions depending on the focus of the question, see figure 3. Agreement was highest with regards to uncertainty over the effects of climate change ( $70 \%$ strongly or tended to agree with this statement) followed by perceived exaggeration of the seriousness of climate change; a full $40 \%$ strongly or tend to agree that climate change is exaggerated. Agreement was lowest with regards to uncertainty that climate change is really happening and perceived scientific (dis)agreement on climate change, which provoked similar proportions of responses.

\section{Figure 3}

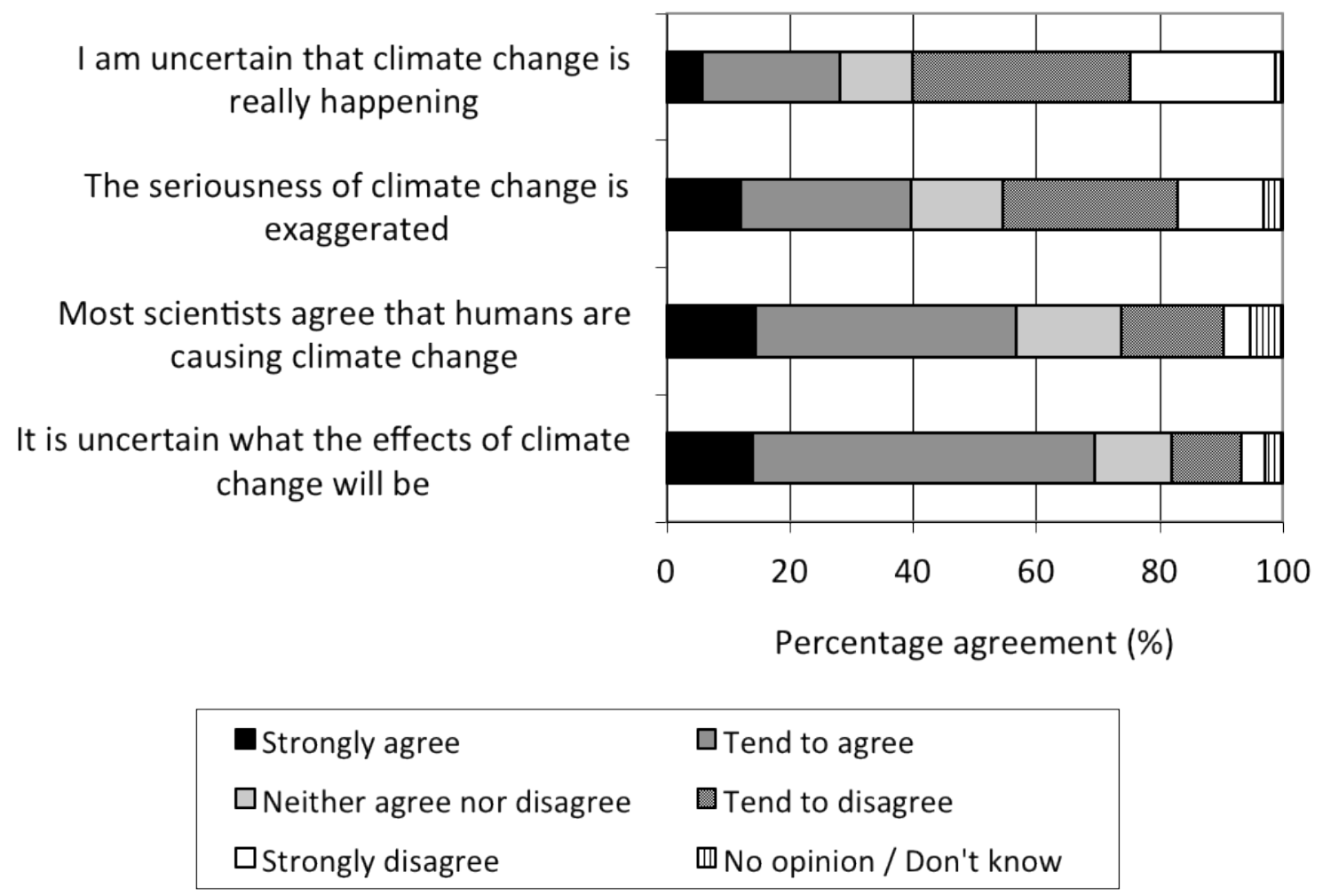

We were also interested in how different aspects of scepticism and uncertainty were related to 
one another. We therefore utilised a principle components analysis on variables relating to scepticism and uncertainty for 1612 respondents (listwise deletion used for this and all other analyses). A scree plot indicated that these formed one coherent component, which explained $44.56 \%$ of the variance in factors examined. However, the factor loading of the item reflecting uncertainty over the effects of climate change did not reach the commonly agreed level of inclusion (0.40) within this and therefore was removed from the analysis (58). Our analysis indicates that although perceived exaggeration, perceived causes, perceived scientific agreement and perceived uncertainty over climate change differ significantly with regards to mean levels of public belief, these do covary with one another indicating that each of these are related in some way. These factors were therefore reversed where necessary and combined in one scale, described as 'uncertainty of climate change' which we use in subsequent analysis (Cronbach's $\alpha$ $=0.71)$ and where higher values indicate a greater level of uncertainty. See XXX (51) for a further analysis of uncertainty data contained here.

\subsection{Relationships Between Psychological Distance Dimensions}

Psychological distance dimensions were reversed for further analyses so that all were examined on scales where higher values indicated greater levels of psychological distance. Correlations between different aspects of psychological distance were all positive and mostly highly significant, which is perhaps unsurprising given our sample size, see Table II. Based on Cohen's guidelines (60) on effect sizes (small: $r=0.1-0.23$; medium: $r=0.24-0.36$; large: $r=0.37$ or larger), we observe that peoples' perceptions of climate change impacts on distant areas has a strong relationship with perceived impacts on developing countries and a moderate relationship with perceived local impacts of climate change. Moderate to large effect sizes were particularly 
noted in all relationships between perceived local impacts of climate change, perceived impacts on people similar to the respondents, temporal distance and uncertainty over climate change. In addition, our analysis indicates that perceptions of climate change impacts on developing countries, whilst correlating strongly with perceptions of distant impacts, and to a lesser extent perceived impact of local areas, did not correlate significantly with any other aspect of perceived distance, indicating that this construct appears to encompass aspects of geographic distance but also considerations different to other aspects of psychological distance.

(Insert Table II about here)

\subsection{Relating Psychological Distance to Concern About Climate Change}

Concern about climate change was quite high with mean levels of concern reported of 2.78 (on a four point scale where higher values indicate greater concern) and a standard deviation of 0.77 . The relationship between perceived psychological distance dimensions and concern about climate change was examined using a forced entry linear regression, see Table III. We found that perceptions that climate change is likely to impact local areas, to impact people perceived to be similar, to occur at closer time scales, and that climate change is perceived as more certain, were all significantly related to higher levels of concern about climate change. Altogether, these different aspects of psychological distance explained around 54\% variance in expressed concern about climate change. Interestingly, considerations of impacts on distant areas and impacts on developing countries were not significantly related to concern about climate change. Note that psychological distance dimensions included in the analysis are largely interrelated and therefore some of the variance in concern explained is overlapping; direct correlational relationships with 
concern are therefore likely to be higher. Collinearity here was not a problem for analysis though with variance inflation factors varying between 1.3 and 1.7 which are considered acceptable.

(Insert Table III about here)

\subsection{Relating Psychological Distance to Preparedness to Act on Climate Change}

Psychological distance dimensions were further regressed on respondents' preparedness to reduce energy use to help tackle climate change, firstly alone, and then in a second step alongside concern to examine the contribution of psychological distance perceptions over and above measures of concern, see Table IV. A similar pattern of results as that observed between psychological distance dimensions and concern was observed here. The perception that climate change is likely to impact areas local to participants, to impact people perceived to be similar, to occur at closer timescales and the perception that climate change is more certain to occur, are significantly related to preparedness to act on climate change. Here we note that perceived impacts on developing countries is also important however. Notably the direction of the relationship between perceived impacts on developing countries and preparedness to reduce energy use is of interest; here the greater the perceived distance (in terms of disproportionate impact on developing countries), the greater the preparedness to act.

A second step in the regression included concern as a predictor of preparedness to reduce energy use alongside dimensions of psychological distance. The second step in the regression demonstrated a significant increase in variance explained in preparedness to reduce energy use by predictors with an $\mathrm{R}^{2}$ change of $0.056(\mathrm{~F}$ change $(1,1548)=114.856, \mathrm{p}<0.001)$. Results indicate that the significance of relationships between key aspects of psychological distance and 
preparedness to act are reduced when concern is included in a regression equation, indicating that concern overlaps with psychological distance variables to some extent and may partially mediate the relationships observed. However, several of these relationships remain significant over and above concern about climate change (albeit explaining much lower amounts of variance compared to concern). Perceived impacts on developing countries and perceived impacts on people similar to the respondents remain important predictors of preparedness to act alongside concern about climate change. Here again note that relationships described are those that remain when all other factors are included in the analysis and direct correlational relationships in the absence of other variables are likely to be slightly higher. Examination of variance inflation factors within the regression analyses indicated that these ranged between 1.3 and 1.7 when distance dimensions were regressed on preparedness to act indicating that collinearity was not an issue. However when concern was included in the analysis, the variance inflation factor for concern was 2.2 indicating that there was some degree of collinearity.

Given the evident overlap between concern about climate change, psychological distance indicators and preparedness to act, we examined the possibility that concern acts as a partial mediator of the relationship between psychological distance and preparedness to act on climate change. A scale of psychological distance was created by combining all dimensions of psychological distance examined (perceived impacts on distant areas, on developing countries, people like me, on my local area, temporal distance, the perception that climate change is not anthropogenic, perceived uncertainty over whether climate change is happening, perceived exaggeration of climate change, and perceived scientific disagreement over climate change); this formed a scale with good reliability (Cronbach's $\alpha=0.74$ ). In order to combine these variables, perceived temporal distance of climate change was recoded from a 7 point scale to a 5 point 
scale to align with the other scales it was combined with. Essentially here we condensed the distant end of the scale so that responses indicating that climate change impacts would be observed in the next 50 years, 100 years or beyond were combined; this also reduced the skew of the scale (see Figure 2). Note that by combining variables into one psychological distance measure, we do not wish to imply that psychological distance dimensions are one dimensional and indeed our descriptive results speak against the interpretation. However the positive correlations noted between variables and previous theory imply some shared underlying common variance which we wish to focus on here. The scale was coded so that higher values indicated greater psychological distance. Mediation was performed using a product of coefficients approach with SPSS script developed for this purpose (61). This method estimated (rather than constrained) the direct effect of psychological distance on preparedness to act so that indirect effects were not overestimated. In addition, due to the strict assumption of normally distributed data within the product of coefficients approach to mediation, this method utilised bootstrapping to resample the data (1000 times) in estimating the indirect effects.

The total relationship between psychological distance variables and preparedness to reduce energy use to tackle climate change was highly significant $(B=-0.573, t=-17.185, p<$ 0.001). The mediation demonstrates that when concern about climate change was included within the analysis, it operates as a significant mediating variable $(Z=-14.492, p<0.001)$, reducing the direct relationship between psychological distance and preparedness to reduce energy use $(B=-0.140, t=-3.365, p<0.001)$. The resulting model explains approximately $25 \%$ of variance in preparedness to reduce energy use (adjusted $R^{2}=0.245, F(2,1785)=591.644, p$ $<0.001)$, see Figure 4. 


\section{Figure 4}

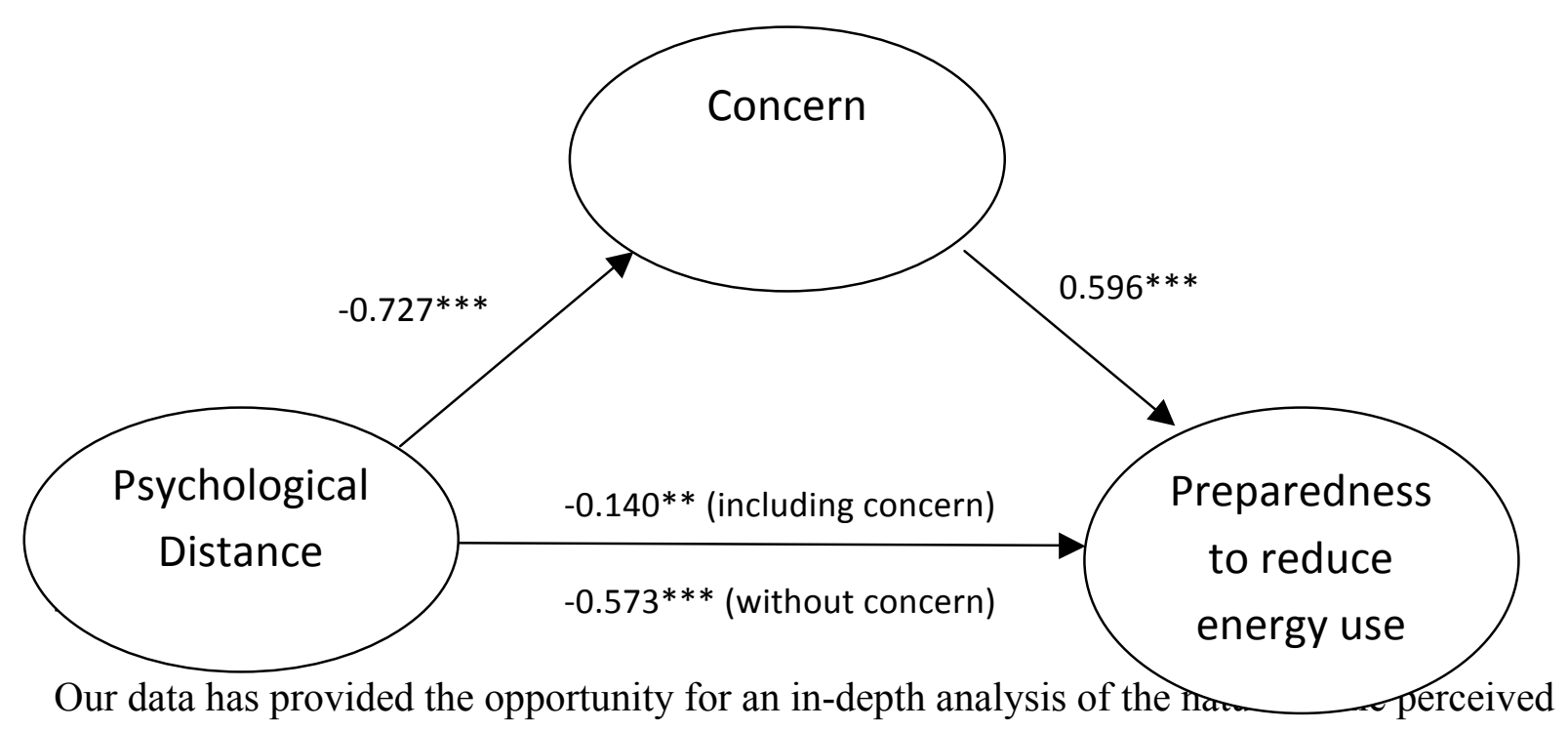

psychological distance of climate change within a national UK population sample. In contrast to much discussion of climate change, our data indicates that climate change risks are perceived as both distant and proximal within certain dimensions of climate change. In line with current debate, a great deal of uncertainty is observed in relation to climate change; however we note that this is highly variable depending on the aspect of climate change science or communications under consideration. Psychological distance dimensions were generally found to have a strong relationship with each other, with only a few key exceptions, supporting the idea that these are interrelated. Generally lower psychological distance was related to higher concern about climate change however, in relation to preparedness to act, key considerations about the impact that climate change may have on developing countries also appeared important. Our results elaborate and elucidate previous research relating to risk communications of climate change, suggesting the importance of highlighting local, but also certain distant, impacts of climate change. 


\subsection{Characterising the Psychological Distance of Climate Change}

Whilst respondents believe that climate change is likely to disproportionately impact developing countries, climate change impacts are also perceived to affect local areas and people similar to themselves and in this sense, climate change is actually psychologically fairly close. Indeed, the majority of people also feel that climate change is temporally close and that Britain has already begun to feel the impacts of climate change.

Supporting current discourses on climate change, we do find significant levels of uncertainty and scepticism in relation to climate change. However, we also find that it is important to distinguish between different aspects of scepticism and uncertainty regarding climate change because perceptions vary greatly depending on the specific aspect of scepticism or uncertainty under consideration. For example, whilst only a quarter of people are uncertain that climate change is happening and most believe that humans contribute to climate change, much larger proportions perceive climate change to be exaggerated. The former may, of course, reflect the impact of increased media reporting and political debate on this issue, rather than a fundamental loss of faith in the underlying science. Also, and perhaps reflecting dominant scientific beliefs, the highest levels of perceived uncertainty expressed are over the effects of climate change possibly indicating that public and scientific opinion may not be as disparate as has previously been suggested (62).

\subsection{Interrelationships between Psychological Distance Dimensions}

Construal level theory postulates that psychological distance dimensions of geographical, social and temporal distance, along with uncertainty have similar cognitive representations, and hence are closely associated with one another. Supporting this idea is a range of mostly 
laboratory-based experiments which find that the manipulation of one aspect of psychological distance has a significant impact on other aspects of distance (4). Here, we find that key psychological distance dimensions of climate change are significantly correlated suggesting that there may indeed be some relationship between these different perceived elements of climate change. However, perceived impacts of climate change on developing countries does not have a consistent relationship with other aspects of psychological distance suggesting that these factors are slightly different from the others measured. This, of course, is a specific aspect of psychological distance that is peculiar to the domain of climate change. Despite these differences, interestingly all aspects of psychological distance are positively correlated and combine to form a reliable scale, again illustrating the commonalities between these concepts, and indicating the potential utility of one overarching concept of psychological distance in future research. We note that here, it is possible that perceived size or significance of climate change impacts could be impacting responses here. Indeed logically, the larger the perceived impacts, the more likely these are to be perceived to affect you or your area and in fact, as observed within the final mediation analysis conducted here, the relationship between concern about climate change and the combined psychological distance scale is high, indicating that these constructs may overlap. However, we suggest that the complexity and differences noted between responses received indicated that participants interpreted individual questions more specifically than this.

Interestingly factor analyses demonstrate that whilst perceptions about different aspects of uncertainty and scepticism differ greatly, these are related in that they vary in a very similar way. So, whilst empirical levels of uncertainty/scepticism differ, individuals who are uncertain about one aspect examined are also likely to be more uncertain on other aspects. This may 
indicate that these different dimensions of uncertainty are linked in some way and/or that these are subject to some common driving factor. The idea that different dimensions of uncertainty may be linked is theoretically consistent with construal level theory; as previously outlined, construal level theory proposes that psychological distance dimensions are represented similarly in the mind and that manipulations of one aspect of distance can affect all other aspects of distance. A logical extension of this idea (which remains to be tested) is the potential for uncertainty transfer, where a change or greater prominence given to one aspect of climate uncertainty could lead to similar changes in other aspects of uncertainty or scepticism.

\subsection{Communicating Climate Change}

The idea of uncertainty transfer has important implications for communicating climate uncertainty because the communication of one kind of uncertainty may have an impact on perhaps wholly unrelated different aspects of uncertainty in relation to climate change; this idea would be usefully followed up with experimental or quasi-experimental studies. In policy terms this would set a difficult communication dilemma, because we are about to move into an era where climate impacts will need to be communicated more forcibly in risk terms $(63,64$, e.g. the UK's 2009 Climate Projections were the first in the world to systematically make local area predictions for a complete country on a Bayesian uncertainty basis, 65), whilst maintaining a narrative that the anthropogenic causes themselves (and the need for aggressive mitigation actions) are certain. Uncertainty, where it exists should clearly be discussed. Given the importance of trust in information on climate change and the increasing emphasis on transparency in science policy more generally, we would suggest that it is important to be open about where uncertainties lie whilst being clear about where research is more certain (e.g. 66). 
Our results also have relevance for the existing risk literature on whether psychological distance on climate change relates to levels of public concern, which is often used as an indicator of risk perception. Results indicated that generally lower psychological distance was associated with higher concern about climate change. Our data implies that, in order to promote concern about climate change, risk communications should focus on making climate change psychologically closer and make potential climate change impacts relevant to individuals' social group, locality, and lifetime. Here, considerations of distant impacts and impacts on developing countries were not so important. We must caution that all relationships observed here are examined within cross-sectional data and therefore causality cannot be identified, only assumed. In relation to promoting action on climate change, relevant psychological distance considerations were slightly different. Our data indicates that, as with relationships with concern, making climate change relevant to the audience's locality and social groups is important in promoting action, as is reducing uncertainty over whether climate change is happening and reducing the perceived temporal distance of effects. However here, the perceived impacts on developing countries were much more important. So here, actually, the greater the disproportionate impacts on distant developing countries that were perceived in relation to climate change (i.e. the greater the psychological distance), the more people were prepared to undertake sustainable behaviour. This indicates that whilst personal, local, closer considerations of climate change are important in promoting concern about climate change, when it comes to promoting action, it may also be important to highlight the wider, global impacts of climate change. This is congruent with earlier studies that find that respondents actually tend to perceive climate change impacts to be more serious at distant locations (36) as well as with theoretical predictions drawn from construal level theory. Construal level theory points to the importance of 
psychological distance in promoting action (4). Previous evidence has demonstrated that focusing on distance helps people to make decisions that are more in line with their core beliefs. Focusing on the implications of climate change for distant developing countries may therefore help people gain perspective on their actions, which may help to explain why these perceptions relate to preparedness to act but not to concern about climate change. Of course, we also found that elements of psychological closeness are important in promoting action which does not support previous theorising within construal level theory. In another way, it could be considered that psychological closeness could be related to stronger intentions to act, if thinking specifically about climate change impacts in terms of a local context might reduce ambiguities about how to act on climate change (26). Psychological closeness and a focus on specific detailed aspects of the situation are highlighted as important for increasing the likelihood of action within goal setting theory. Goal setting theory would suggest that considering psychologically close impacts of climate change should help to direct attention and effort towards relevant actions, can activate task relevant knowledge, and may energise the individual and increase persistence on actions attempted. It appears therefore that our results indicating that both psychological closeness and psychological distance are important in encouraging people to act on climate change supports elements of both construal level theory and goal setting theory. This also supports the findings of Rabinovitch et al (34) which indicate that a combination of both an abstract mindset and specific goals may have most utility in promoting climate change related behaviour. Indeed as discussed earlier, predictions of construal level theory and goal setting theory are not necessarily incompatible given the slightly differing focus of each (construal level theory focusing on translating core values into behaviour and goal setting theory focusing on translating intentions into action). We do want to highlight that we examined only behavioural intentions here, not 
actual behaviour which might benefit from a psychological distance or closeness that we cannot examine here.

Notably, we find that concern has the strongest relationship with preparedness to act, greatly reducing the influence of psychological distance dimensions on preparedness to act (and acting as a significant partial mediator of this relationship). However certain key psychological distance variables retained significant relationships with preparedness to act over and above concern about climate change indicating that communications regarding psychological distance may be useful for a range of sectors of society, including those who already express high concern on climate change.

\section{CONCLUSIONS}

Current discussions and debate on climate change frequently refer to the psychological distance of climate change. However there has been little in-depth empirical analysis of the operation of this perceived distance and only limited transfer of these ideas to risk communication strategies. Our results indicate that the UK public really perceive climate change as global, being both distant and local in nature. We observe differences in levels of uncertainty about different aspects of climate change and note that there is a possibility of transfer between different aspects of uncertainty, highlighting the problematic nature of media representations of apparent public uncertainty over climate change. Overall, our findings point to the utility of risk communication techniques designed to reduce psychological distance and to engage the general public with climate change. However, we note that certain aspects of psychological distance, particularly considerations of the potentially very serious distant impacts of climate change, may also be useful in promoting sustainable behaviour. 


\section{References}

1. Brechin, S.R. (2010) Public opinion: a cross-national view. In C. Lever-Tracy (ed.) The Routledge Handbook of Climate Change and Society. London: Routledge, pp. 179-209.

2. Spence, A. and Pidgeon, N.F. (2009). Psychology, climate change and sustainable behaviour. Environment, 51(6), 8-18.

3. American Psychological Association (2010). Psychology and Global Climate Change. APA.

4. Liberman, N., and Trope, Y. (2008). The psychology of transcending the here and now. Science, 322, 1201-1205.

5. Milfont, T. L. (2010). Global warming, climate change and human psychology. In V. Corral-Verdugo, C. H. Garcia-Cadana \& M. Frias-Arment (Eds.) Psychological approaches to sustainability: Current trends in theory, research and practice (pp 19-42). New York: Nova Science.

6. Rayner, S., Malone, E.L., 1997. Zen and the art of climate maintenance. Nature 390, $332-334$.

7. Lorenzoni, I. and Pidgeon, N., 2006. Public views on climate change: European and USA perspectives. Climatic Change 77, 73-95.

8. Spence, A., Poortinga, W., Butler, C. and Pidgeon, N. (2011). Perceptions of climate change and willingness to save energy related to flood experience. Nature Climate Change. 1, 46-49.

9. Defra (Department for Environment, Food and Rural Affairs, 2006). Attitudes to Climate Change-Wave 3. HM Government: UK.

10. Poortinga W., Pidgeon, N.F. and Lorenzoni, I. (2006). Public Perceptions of Nuclear 
Power, Climate Change and Energy Options in Britain: Summary Findings of a Survey Conducted during October and November 2005. Technical Report (Understanding Risk Working Paper 06-02). Norwich: Centre for Environmental Risk.

11. Pidgeon, N.F., Lorenzoni, I. and Poortinga, W. (2008). Climate change or nuclear power - no thanks! A quantitative study of public perceptions and risk framing in Britain. Global Environmental Change, 18, 69-85.

12. Leiserowitz, A., Maibach, E., Roser-Renouf, C., \& Smith, N. (2010) Climate change in the American Mind: Americans' global warming beliefs and attitudes in January 2010. Yale University and George Mason University. New Haven, CT: Yale Project on Climate Change Communication.

13. Department for Transport (2010). Public Attitudes Towards Climate Change and the Impact of Transport: 2006, 2007, 2008, and 2009 (January 2010 report). Available at: http://www.dft.gov.uk/pgr/statistics/datatablespublications/trsnstatsatt/climatechngeandtr anport1 Accessed 13th May 2010.

14. Eurobarometer (2009). Europeans attitudes towards climate change (Special Eurobarometer 332). Europe: European Commission. Available at: http://ec.europa.eu/public_opinion/archives/ebs/ebs_322_en.pdf (accessed July 2010).

15. BBC News (2009a). 'UN body wants probe of climate e-mail row'. Available at: http://news.bbc.co.uk/1/hi/8394483.stm Accessed 12th May 2010.

16. BBC News (2009b). 'Himalayan glaciers melting deadline 'a mistake'. Available at: http://news.bbc.co.uk/1/hi/8387737.stm Accessed 12th May 2010.

17. EDF/YouGov (2010). YouGov/EDF Energy Survey Results. Available at: http://www.today.yougov.co.uk/sites/today.yougov.co.uk/files/YG-Archives-Pol-EDF- 
energy-130510.pdf Accessed 4th June 2010.

18. Energy Saving Trust (2007). Green barometer: Measuring environmental attitudes. Energy Saving Trust, London.

19. Bord, R. J., Fisher, A. and O’Connor, R. E. (1998). Public perceptions of global warming: United States and international perspectives. Climate Research 11, 75-84.

20. Bar-Anan, Y., Liberman, N., Trope, Y., and Algom, D. (2007). Automatic processing of psychological distance: Evidence from a stroop task. Journal of Experimental Psychology: General, 136, 610-622.

21. Förster, J., Friedman, R., \& Liberman, N. (2004). Temporal construal effects on abstract and concrete thinking: Consequences for insight and creative cognition. Journal of Personality and Social Psychology, 87, 177-189.

22. Wakslak, C. J., Trope, Y., Liberman, N. and Alone, R. (2006). Seeing the forest when entry is unlikely: probability and the mental representation of events. Journal of Experimental Psychology: General, 135, 641.

23. Smith, P. K. and Trope, Y. (2006). You focus on the forest when you're in charge of the trees: Power priming and abstract information processing. Journal of Personality and Social Psychology, 90, 578-596.

24. Liberman, N., Trope, Y., McCrae, S. M., and Sherman, S. J. (2007). The effect of level of construal on the temporal distance of activity enactment. Journal of Experimental Social Psychology, 43, 143-149.

25. Liberman, M. D., Gaunt, R., Gilbert, D. T. and Trope, Y. (2002). Reflexion and reflection: A social cognitive neuroscience approach to attributional inference. In M. P. Zanna (Ed), Advances in Experimental Social Psychology (Vol. 34, pp. 199-249). New 
York: Academic Press.

26. Locke, E. A. and Latham, G. P. (2002). Building a practically useful theory of goal setting and task motivation: A 35-year odyssey. American Psychologist. 57, 705-717.

27. Locke, E. A. and Latham, G. P. (1990). A theory of goal setting and task performance. Englewood Cliffs, NJ: Prentice Hall.

28. Locke, E. A., Chah, D., Harrison, S. \& Lustgarten, N. (1989). Separating the effects of goal specificity from goal level. Organizational Behaviour and Human Performance, 43, 270-287.

29. Rothkopf, E. \& Billington, M. (1979). Goal-guided learning from text: Inferring a descriptive processing model from inspection times and eye movements. Journal of Educational Psychology, 71, 310-327.

30. Bryan, J. \& Locke, E. (1967). Goal setting as a means of increasing motivation. Journal of Applied Psychology, 51, 274-277.

31. Sales, M. (1970). Some effects of role overload and role underload. Organizational Behaviour and Human Performance, 5, 592-608.

32. Wood, R. \& Locke, E. (1990). Goal setting and strategy effects on complex tasks. In B. Staw \& L. Cummings (Eds.), Research in organizational behaviour (Vol. 12, pp 73-109). Greenwich, CT: JAI Press.

33. Gollwitzer, P. M. (1993). Goal achievement: The role of intentions. In W. Stroebe \& M. Hewstone (Eds.), European Review of Social Psychology (Vol. 4, pp. 141-185). Chicester: Wiley.

34. Rabinovich, A., Morton, T. A., Postmes, T. and Verplanken, B. (2009). Think global, act local: the effect of goal and mindset specificity on willingness to donate to an 
environmental organisation. Journal of Environmental Psychology, 29, 391-399.

35. Leiserowitz, A., Maibach, E., Roser-Renouf, C., \& Smith, N. (2010) Climate change in the American Mind: Americans' global warming beliefs and attitudes in January 2010. Yale University and George Mason University. New Haven, CT: Yale Project on Climate Change Communication.

36. Spence, A. and Pidgeon, N. F. (2010). Framing and Communicating Climate Change: The Effects of Distance and Outcome Frame Manipulations. Global Environmental Change, 20, 656-667.

37. IPCC, 2007. Climate Change 2007: Impacts, Adaptation and Vulnerability. Contribution of Working Group II to the Fourth Assessment Report of the Intergovernmental Panel on Climate Change, M.L. Parry, O.F. Canziani, J.P.

38. Palutikof, P.J. van der Linden and C.E. Hanson (Eds.). Cambridge University Press, Cambridge, UK.

39. Dunlap, R. E., Gallup, G. H., and Gallup, A. M. (1993). ‘Of global concern’: Results of the health of the planet survey. Environment, 35, 7-15.

40. Gifford, R., Scannell, L., Lormos, C., Smolova, L. and Uzzell, D. (2009). Temporal pessimism and spatial optimism in environmental assessments: An 18-Nation study. Journal of Environmental Psychology, 29, 1-12.

41. Uzzell, D. (2000). The psycho-spatial dimension to global environmental problems. Journal of Environmental Psychology, 20, 4, 307-318.

42. Rathzel, N. and Uzzell, D. (2009). Changing Relations in Global Environmental Change. Global Environmental Change. 19, 326-335.

43. Weber, E. U. (2006). Experience-based and description-based perceptions of long-term 
risk: Why global warming does not scare us (yet), Climatic Change, 77, 103-120.

44. Lorenzoni, I., Nicholson-Cole, S. and Whitmarsh, L. (2007). Barriers perceived to engaging with climate change among the UK public and their policy implications. Global Environmental Change, 17, 445-459.

45. Sagristano, M., Trope, Y. And Liberman, J. (2002). Time-dependent gambling: Odds now, money later. Journal of Experimental Psychology: General. 131, 364.

46. Ainslie, G. (1975). 'Specious reward: A behavioural theory of impulsiveness and impulse control'. Psychological Bulletin, 82, 463-496.

47. Loewenstein, G. and Elster, J. (eds.), (1992). Choice Over Time. New York: Russell Sage.

48. Weber, E. (2010). What shapes perceptions of climate change? Wiley Interdisciplinary Reviews: Climate Change 1, 332-342.

49. Weber, E. U., Johnson, E. J., Milch, K., Chang, H., Brodscholl, J. and Goldstein, D. (2007). Asymmetric discounting in intertemporal choice: A query theory account. Psychological Science, 18, 516-523.

50. Rabinovich, A., Morton, T., Postmes, T. (2010). Time perspective and attitude-behaviour consistency in future-oriented behaviours. British Journal of Social Psychology, 49, 6989.

51. Spence, A., Venables, D., Pidgeon, N., Poortinga, W. and Demski, C. (2010). Public Perceptions of Climate Change and Energy Futures in Britain: Summary Findings of a Survey Conducted in January-March 2010. Technical Report (Understanding Risk Working Paper 10-01). Cardiff: School of Psychology.

52. MORI (2007). Social Marketing and Climate Change: Tipping point or Turning point? 
Ipsos MORI, UK.

53. Langer, G. (2008). ABC News/Planet Green/Stanford Poll: Environment/Energy. Available at http://woods.stanford.edu/research/surveys.html . Accessed 04/11/09.

54. Patt, A. and Dessai, S. (2005). Communicating uncertainty: lessons learned and suggestions for climate change assessment. Geoscience, 337, 425-441.

55. Kahneman, D. and Tversky, A. (1979). Prospect Theory: An Analysis of Decision under Risk. Econometrica, 47, 263-292.

56. Stoll-Kleemann, S., O'Riordan, T. and Jaeger. C. C. (2001). The psychology of denial concerning climate mitigation measures: Evidence from Swiss focus groups. Global Environmental Change, 11, 107-18.

57. Kortenkamp, K. V. and Moore, C. F. (2006). Time, uncertainty, and individual differences in decisions to cooperate in resource dilemmas. Personality and Social Psychology Bulletin, 32, 603-615.

58. Xxx (2010) (Anonymised for review purposes).

59. Ferguson E, and Cox, T. (1993). Exploratory factor analysis A users guide. International Journal of Selection and Assessment. 1, 84 - 94.

60. Cohen, J. (1992). A power primer. Psychological Bulletin, 112, 155-159.

61. Preacher K., J., and Hayes, A. F. (2008). SPSS Macro for Multiple Mediation. Available at www.comm.ohio-state.edu/ahayes/

62. Weber, E. U. \& Stern, P. C. (2011). Public understanding of climate change in the United States. American Psychologist, 66, 315-328.

63. Pidgeon, N. F. and Fischhoff, B. (2011). The role of social and decision sciences in communicating uncertain climate risks. Nature Climate Change, 1, 35-41. 
64. Pidgeon, N. F. and Butler, C. (2009). Risk analysis and climate change. Environmental Politics. 18, 670-688.

65. DEFRA (2009). Adapting to Climate Change: UK Climate Projections. DEFRA, London.

66. Somerville, R.C.J. (2011). How much should the public know about climate science? Climatic Change. 104, 509-514. 
Table I - Demographic characteristics of population sample

\begin{tabular}{|c|c|c|c|c|c|}
\hline Characteristic & & $\%$ & Characteristic & & $\%$ \\
\hline \multirow[t]{3}{*}{ Gender } & Male & 48 & $\begin{array}{l}\text { Employment } \\
\text { Status }\end{array}$ & Working (full-time) & 36 \\
\hline & Female & 52 & & Working (part-time) & 13 \\
\hline & & & & Unemployed & 8 \\
\hline \multirow[t]{8}{*}{ Age } & $15-17$ & 3 & & Retired & 27 \\
\hline & $18-24$ & 12 & & $\begin{array}{l}\text { Looking after house / } \\
\text { children }\end{array}$ & 7 \\
\hline & $25-34$ & 14 & & Disabled & 3 \\
\hline & $35-44$ & 18 & & Student & 7 \\
\hline & $45-54$ & 17 & & Other & $*$ \\
\hline & $55-64$ & 14 & & & \\
\hline & $65-74$ & 13 & & & \\
\hline & 75 and older & 9 & & & \\
\hline
\end{tabular}

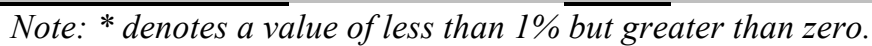


Table II - Correlations between different psychological distance dimensions

$\begin{array}{llllll}1 & 2 & 3 & 4 & 5 & 6\end{array}$

\begin{tabular}{l}
\hline 1. Impacts on distant \\
areas \\
$\begin{array}{ll}\text { 2. Impacts on my } & 0.243 * * * \quad 1 \\
\text { local area } & \end{array}$
\end{tabular}

\section{Impacts on $\quad 0.446 * * * \quad 0.089 * * * \quad 1$}

developing countries

4. Impacts on people $\begin{array}{lllll}0.117 * * * & 0.552 * * * & -0.006 & 1\end{array}$

like me

$\begin{array}{lllllll}\text { 5. Temporal distance } & 0.078 * * * & 0.455^{* * *} & -0.041 & 0.391 * * * & 1 & \\ \text { 6. Uncertainty over } & 0.141 * * * & 0.427 * * * & -0.005 & 0.438 * * * & 0.452 * * * & 1 \\ \text { climate change } & & & & & & \end{array}$

Note: Based on a sample of $N=1573$ (using listwise deletion); *** $p<0.001$. 
Table III - Regression of psychological distance dimensions on concern about climate change

\section{Concern}

\begin{tabular}{ll}
\hline Impacts on distant areas & 0.014
\end{tabular}
Impacts on my local area
$-0.176^{* * *}$

\begin{tabular}{ll} 
Temporal distance & $-0.119^{* * *}$ \\
\hline Uncertainty over climate change & $-0.350^{* * *}$
\end{tabular}

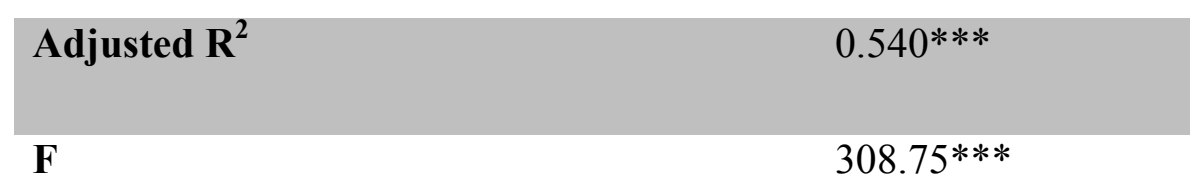

Note: Based on a sample of $\mathrm{N}=1572$ (using listwise deletion). ${ }^{* * *} \mathrm{p}<0.001$. Coefficients are all standardized Beta coefficients. All variables are scored so that higher levels of the factor indicate higher or more extreme levels of that construct, e.g. higher scores for concern indicate higher levels of concern. 
Table IV - Regression of psychological distance dimensions and concern on preparedness to act

\begin{tabular}{lll}
\hline & $\begin{array}{l}\text { Preparedness to } \\
\text { reduce energy use }\end{array}$ & $\begin{array}{l}\text { Preparedness to } \\
\text { reduce energy use }\end{array}$ \\
\hline Impacts on distant areas & (Step 1) & (Step 2) \\
\hline Impacts on my local area & 0.000 & -0.005 \\
\hline Impacts on developing countries & $-0.101^{* * *}$ & -0.039 \\
\hline Impacts on people like me & $0.077^{* *}$ & $0.069 * *$ \\
\hline Temporal distance & $-0.189^{* * *}$ & $-0.083 * *$ \\
\hline Uncertainty over climate change & $-0.077^{*}$ & -0.035 \\
\hline Concern & $-0.178^{* * *}$ & -0.055 \\
\hline Adjusted R & & $0.352^{2}$ \\
\hline F & & $0.239^{* * *}$ \\
\hline
\end{tabular}

Note: Based on a sample of $N=1556$ (using listwise deletion). ${ }^{*} p<0.05,{ }^{* *} p<0.01,{ }^{* * *} p<0.001$. Coefficients are all standardized Beta coefficients. All variables are scored so that higher levels of the factor indicate higher or more extreme levels of that construct, e.g. higher scores for concern indicate higher levels of concern. 


\section{Figure Legends}

Figure 1 - Perceived geographic and social distance of climate change

Respondents' agreement with each statement is provided in percent.

\section{Figure 2 - Perceived temporal distance of climate change}

Respondents were asked, 'When, if at all, do you think Britain will start feeling the effects of climate change?'. Percent agreement with each potential response option is provided.

\section{Figure 3 - Perceived uncertainty and skepticism surrounding climate change}

Respondents' agreement with each statement is provided in percent.

\section{Figure 4 - Concern as a mediator of psychological distance on preparedness to act}

Values provided are unstandardised coefficients indicating the strength of the relationship between variables. Note: ${ }^{*} \mathrm{p}<0.05,{ }^{*} \mathrm{p}<0.01,{ }^{* * *} \mathrm{p}<0.001$. All variables are scored so that higher levels of the factor indicate higher or more extreme levels of that construct, e.g. higher scores for concern indicate higher levels of concern. 


\section{Appendix - Questions assessing perceptions and behavioural intentions}

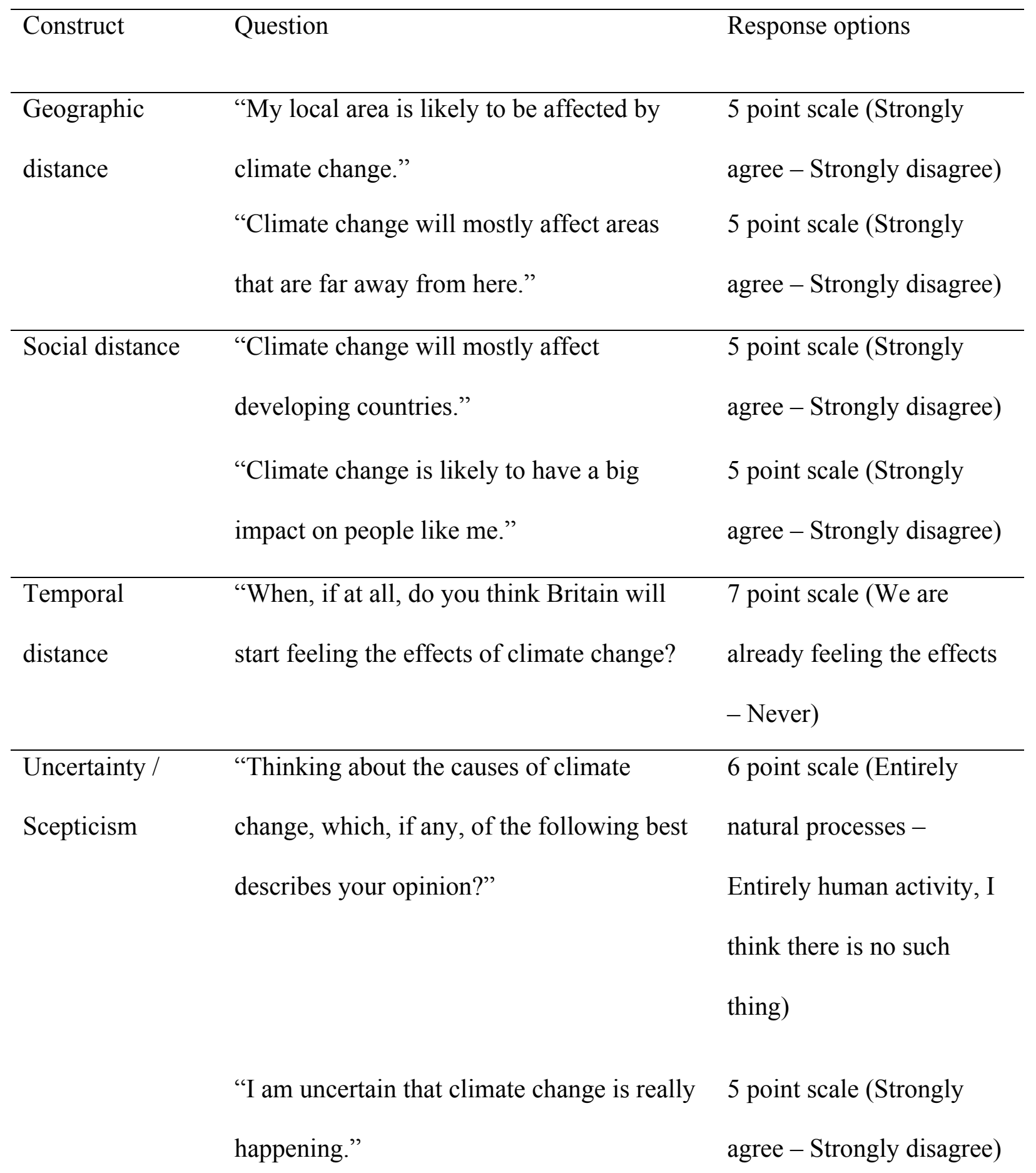


"The seriousness of climate change is exaggerated."

"Most scientists agree that humans are causing climate change."

"It is uncertain what the effects of climate change will be."
5 point scale (Strongly

agree - Strongly disagree)

5 point scale (Strongly

agree - Strongly disagree)

5 point scale (Strongly

agree - Strongly disagree)

4 point scale (Very

concerned - Not at all

concerned)

"Considering any potential effects of climate

change which there might be on you

personally, how concerned, if at all, are you

about climate change?"

“Considering any potential effects of climate

change there might be on society in general,

how concerned are you about climate

change?"

$\begin{array}{lll}\text { Preparedness to } & \text { "I am prepared to greatly reduce my energy } & 5 \text { point scale (Strongly } \\ \text { act } & \text { use to help tackle climate change." } & \text { agree - strongly disagree) }\end{array}$

